Voix et Images

volxetimages

\title{
Agenor, Agenor, Agenor et Agenor de François Barcelo
}

\section{Gaëtan Lévesque}

Volume 7, numéro 2, hiver 1982

Michel Tremblay

URI : https://id.erudit.org/iderudit/200335ar

DOI : https://doi.org/10.7202/200335ar

Aller au sommaire du numéro

Éditeur(s)

Les Presses de l'Université du Québec

ISSN

0318-9201 (imprimé)

1705-933X (numérique)

Découvrir la revue

Citer cet article

Lévesque, G. (1982). Agenor, Agenor, Agenor et Agenor de François Barcelo.

Voix et Images, 7(2), 423-424. https://doi.org/10.7202/200335ar d'utilisation que vous pouvez consulter en ligne.

https://apropos.erudit.org/fr/usagers/politique-dutilisation/ 
Roman

\section{Agenor, Agenor, Agenor et Agenor de François Barcelo}

\section{par Gaëtan Lévesque}

Depuis Quand la voile faseille de Noël Audet' et La Saga des Lagacé d'André Vanasse ${ }^{2}$, peu nombreux sont les romanciers qui ont manié d'une main de maître, un genre littéraire qui demande une aussi grande dextérité que le récit humoristique. François Barcelo réussit ce tour de force littéraire dans son premier roman: Agénor, Agénor, Agénor et Agénor ${ }^{3}$.

Au départ, le titre ne laisse supposer rien de plus qu'un nom, qu'on n'entend pas tous les jours mais qui est répété comme une espèce d'écho "visuel" qui invite à la lecture de ce merveilleux roman de 320 pages que le lecteur trouve trop court tant l'écriture de Barcelo est envoûtante et ses personnages attachants.

L'auteur situe son récit entre le $X \mid X e$ et le $X X e$ siècles et ses personnages évoluent dans un espace imaginaire qui pourrait-être «aussi bien le Québec, que n'importe quel autre pays" tandis que l'action se déroule entre l'humour et la tendresse. A partir de certains jeux de mots, Barcelo nous plonge dans un univers fictionnel, plein d'imagination, qui pourrait aussi bien refléter la réalité.

Les principaux rôles de cette "superproduction romanesque" sont tenus par des femmes, dont celui de Marie-Clarina, femme forte et sympathique, qui est présente du début à la fin du récit. Et c'est autour de ce personnage principal que les personnages secondaires viennent se greffer; au total, 23 chapitres, dans lesquels évoluent une douzaine de personnages des plus impressionnants. Chaque acteur à droit à un chapitre de présentation dans lequel l'auteur s'en donne à cceur joie, nous racontant les antécédents de chacun d'eux. De cette manière, il réussit à situer ses personnages par rapport aux autres sans nous faire perdre le fil de la narration. II faut beaucoup de talent pour jouer avec autant de personnages et réussir à rendre une histoire intéressante.

Que ce soit, Agénor, l'extraterrestre ou Agénor, le militaire, Barcelo dessine de façon originale le caractère et la personnalité de chaque individu dans le milieu social et individuel dans lequel il évolue. Autant les scènes de guerre sont sanglantes et décadentes, autant les scènes d'amour sont belles et tendres. C'est une vision de l'érotisme qui n'est pas gratuite. 
Du reste rien n'est gratuit dans ce roman. Chaque élément romanesque à sa raison d'être. Chaque histoire s'insère dans le plan global pour nous donner un récit éminemment bien construit.

Par son originalité, Agénor... est un des romans importants de 1980 et son auteur s'insère dans la lignée des meilleurs écrivains québécois. Il est à espérer que François Barcelo nous offrira bientôt d'autres histoires aussi captivantes.

1. Noël Audet, Quand la voile faseille, Montreal, Ed. Hurtubise, coll. L'Arbre, $1980,312 \mathrm{p}$.

2. André, Vanasse, La Saga des Lagacé, Montréal, Ed. Libre Expression, 1980, $168 \mathrm{p}$.

3. François Barcelo, Agenor, Agenor, Agenor et Agenor, Montréal, Ed. Quinze, coll. Prose entière, 1980, 320 p. 